\title{
Trade and convergence of per capita income in the Indian Ocean Zone, 1950-2008
}

\author{
Olivier Peron · Serge Rey
}

\begin{abstract}
This empirical study of per capita income convergence across the countries of the Indian Ocean Zone (IOZ) during 1950-2008 relies on a distribution dynamics approach that employs both stochastic kernels (stacked and high-density region plots) and a nonparametric estimator. During this period, no absolute convergence process of incomes occurs in the IOZ. Nevertheless, a bipolar situation emerges, such that countries with the weakest relative incomes in relation to the IOZ average remain in the same relative position - that is, the poorest countries remain poor. The relatively richest countries (i.e., Australia, Malaysia, Mauritius, Singapore, and Thailand) constitute a convergence club. Use of conditioned distributions shows that the dynamics of per capita gross domestic product (GDP) distributions can be explained both by the openness rate measured as trade/GDP ratio, or a proxy for trade policy, and by manufactured goods exports. However, this result likely confirms that the openness was accompanied by an increase in manufactured goods trade for many of these countries. In addition, openness defined following Sachs and Warner has a less explanatory power than traditional measure. Finally, bilateral trade and trade agreements have limited effects.
\end{abstract}

JEL Classification $\quad \mathrm{C} 13 \cdot \mathrm{C} 16 \cdot \mathrm{F} 43 \cdot \mathrm{O} 47$

\footnotetext{
O. Peron $\cdot$ S. Rey $(\varangle)$

Department of Economics, C.A.T.T., University of Pau et Pays de 1'Adour, Avenue du Doyen Poplawski, B.P. 1633, 64016 Pau Cedex, France

e-mail: Serge.rey@univ-pau.fr

O. Peron

e-mail: Olivier.peron@univ-pau.fr
} 


\section{Introduction}

For many centuries, the countries of the Indian Ocean Zone (IOZ) have shared a common history in which trade played a fundamental role. After World War II, the decolonization process ended hegemony by European nations. Though always partly bound to old colonial powers (e.g., as commonwealths), these countries initiated a process of development, with greater openness and liberalization in their economies. Naturally, they relied on the Indian Ocean to develop their exchanges and support their growth. This liberalization trend was reinforced by different regional agreements (see Appendix 1). With these similar patterns, an important question arises: Do the real per capita incomes of member countries tend to converge or diverge? In other words, do trade relations favor the convergence of per capita incomes in the IOZ?

From a general perspective, economists have debated whether different countries converge over time in their per capita income. For example, Sala-i-Martin (1990, $1996 \mathrm{a}, \mathrm{b})$ introduces the terms $\beta$-convergence, which postulates that poor economies tend to grow faster than rich economies, and $\sigma$-convergence, which indicates that the dispersion of real per capita incomes tends to decrease over time. Other authors offer "evidence that low income economies tend to grow faster than high-income economies, after controlling for rates of savings and population" (Durlauf 1996, p. 1016), which suggests conditional convergence and generally supports a neoclassical growth model. Yet Quah (1996a) instead uses a theoretical model that describes economic forces that determine the formation of specific convergence clubs:

When different convergence clubs form, factor inputs (e.g., human capital) and social characteristics (e.g., democracy) will endogenously align around values determined by each country's convergence club. Conditioning on such "explanatory variables" leads the researcher using the traditional approach to conclude, erroneously, that it is those variables that determine a country's economic position. By contrast, in the model, it is the factors deciding club membership that determine everything. The traditional researcher never finds and incorrectly attributes growth and convergence to factor inputs and social characteristics. (Quah 1996b, p. 1053)

We analyze the evolution of per capita incomes to highlight a possible process of convergence within the group of 16 IOZ countries. By retaining Quah (1996a) distribution perspective, we posit that each country's income may follow a Markov process with time-invariant transition probabilities. Following Basile (2010), we also choose the method of Hyndman (1996) developed to estimate stochastic kernels. In addition, we privilege high-density region (HDR) plots to depict the conditional density. Because we also are interested in the influence of trade relationships in this process, we study the principal countries that constitute the Indian Ocean Rim for Regional Cooperation (IOR-ARC), as well as two additional countries with strong links to the group, namely, Seychelles and Pakistan. However, we exclude oil producers, whose gross domestic product (GDP) depends almost exclusively on oil prices. Therefore, our sample of 16 countries includes Australia, Bangladesh, India, Indonesia, Kenya, Madagascar, Malaysia, Mauritius, 
Mozambique, Pakistan, Seychelles, Singapore, Sri Lanka, South Africa, Tanzania, and Thailand.

Although some trade agreements are relatively recent, we analyze the convergence process of per capita incomes during the 1950-2008 period. We extract the pertinent data from Maddison (2010) ${ }^{1}$ work. We organize the remainder of this article as follows: Sect. 2 presents a brief review of the literature on the relationship among trade, growth, and the process of convergence. Section 3 reveals information on the distributions of the per capita incomes of the studied countries for 1950, 1975, 2000, and 2008. To measure the convergence of real GDP per capita, in Sect. 4, we present evidence of stochastic convergence (Bernard and Durlauf 1996) and of the stochastic kernel (Quah 1996b; Hyndman et al. 1996). Section 5 illustrates the role of trade conditioning in explaining the dynamics of income distribution. We conclude in Sect. 6.

\section{Trade, growth, and convergence or divergence?}

We examine whether trade liberalization is favorable to convergence and argue that the answer can be ambiguous, at both the theoretical level and the empirical level. In the traditional Solow neoclassical model, convergence emerges in a closedeconomy process. Accordingly, this model may not account for the role of international trade. Conversely, endogenous growth models, pioneered by Romer (1986) and Lucas (1988), provide theoretical foundations to explain this relationship. With this perspective, trade flows facilitate the diffusion of knowledge between partner countries and spur the growth process.

To examine this relationship more precisely, we need to distinguish the relationship between trade and growth on the one hand and the relationship between growth and convergence or divergence on the other hand. The literature reveals many transmission channels by which trade "causes" growth and therefore leads to convergence or divergence. We present a brief summary next.

\subsection{The real exchange rate}

In the tradition of the Australian or Scandinavian schools, we can define the real exchange rate as the relative price of tradable and non-tradable goods, which is an appropriate definition for developing countries (Edwards 1987). Before the liberalization of economies, tariff measures are applied to imports. ${ }^{2}$ If the economy opens, this results in a gradual reduction of tariffs and therefore an appreciation of the real exchange rate (i.e., the relative price of traded goods was lower). The tradable goods price, which comprises importable price and exportable price, diminishes further because import tariffs are reduced or even eliminated. Besides, the presence of taxes on exports also promotes the domestic market. In this case, the effects of a change of export taxes depend on the size of the country (Bouët and Laborde Debucquet 2010).

\footnotetext{
1 Last updated March 2010. See http://www.ggdc.net/maddison/.

2 This was also the case for export subsidies (see Edwards 1993).
} 
For example, if the country is small (price-taker), lower export taxes may generate an increase in exportable price. If the country is large, which is true for many developing countries that produce raw materials, the change in export taxes can be offset by a change in the world price of commodities (Winters et al. 2004). In this case, lower export taxes lead to an increase in exports and a lower world price, insofar as the large country is assumed to export a significant share of world exports. Therefore, the total effect on tradable price can be ambiguous. Finally, the search for productivity gains in the tradable sector (Balassa/Samuelson bias) may accentuate the movement.

On the whole, if we start from an equilibrium position (neither overvaluation nor undervaluation), openness leads to an overvaluation of domestic currency. In the absence of nominal exchange rate adjustment, lower relative price of traded goods will result in a transfer of resources to the sector sheltered from international competition. Because this sector is less productive, it will mean a slowdown in growth. ${ }^{3}$

\subsection{Technology diffusion}

Investment in research and development is a powerful engine of growth because of productivity gains. In addition, research and development has beneficial effects for trading partners. Among other researchers, Coe and Helpman (1995) emphasize the role of technology diffusion in the case of industrialized countries. However, a developing country that liberalizes its trade with industrial countries may also benefit from technology transfers (reducing the technological gap; see Krugman 1985), enabling it to increase its productivity and thereby its growth (see Coe et al. 1997). Trade openness/trade liberalization contributes to these transfers through several mechanisms.

- First, enhanced relationships with external agents will assist in the transmission of knowledge, promoting learning and development of new production methods, and a more efficient work organization. Therefore, when a country opens, it will imitate production methods, which necessitates incorporating new technologies. Japan, and more recently China, has shown that imitation can be an engine of growth. In addition, trade will contribute to acquisition of human capital (Easterly et al. 1993), and "human capital generally contributes positively to total factor productivity" (Miller and Upadhyay 2000, p. 399). ${ }^{4}$

- Second, if the country imports intermediate goods, all products will benefit from higher technological content, through the input-output relationships. In addition, import of capital goods with high technological content will promote productivity gains, which will increase efficiency of investment. The positive effects of liberalization on investment can be great (Baldwin and Seghezza 1996). On the one hand, imports of intermediate goods with high technological content will encourage domestic production of capital goods. On the other hand, economic openness

\footnotetext{
${ }^{3}$ In the long run, consequences could be different if the country adopts changes in its exchange rate policy, its industrial policy, and so forth.

${ }^{4}$ In poor countries, human capital interacts with openness to achieve a positive effect.
} 
will promote the development of the traded goods sector, which is more capitalintensive than the non-tradable sector. Finally, the investment will be promoted through competition on international markets for capital equipment that in turn will lower prices. The works of Levine and Renelt (1992), Baldwin and Seghezza (1996), Wacziarg (1998), and Vamvakidis (1999) confirm this hypothesis. "Trade appears to raise income by spurring the accumulation of physical and human capital and by increasing output for given levels of capital" (Frankel and Romer 1999, p. 394).

- Third, faster growth of external demand (trading partner's GDP) means export growth; this refers to the so-called export-led growth hypothesis. By pushing the limits that domestic demand imposes on growth, exports allow for the exploitation of economies of scale to beat diminishing returns. ${ }^{5}$ Among exports, manufactured goods exports, which use more capital-intensive techniques, assume a privileged role. "Manufactured goods have more learning potential than agricultural products" (Chuang 1998, p. 702).

- Fourth, beyond the positive effects that countries receive through the exchange of goods and services, opening up to foreign direct investment (FDI) by multinational corporations will help strengthen the previous three mechanisms. That is, FDI may increase the process of technology diffusion because firms introduce new varieties of capital goods. Therefore, FDI may boost the productivity of all firms as well as the entire economy. However, the introduction of more advanced technology requires a sufficient level of human capital in the host country (Borenztein et al. 1998).

\subsection{Free-trade agreements}

Using a more restrained framework, we distinguish several effects of the free-trade agreements between low- and high-income countries. As Venables (1999, 2003) shows, the influence of trade agreements depends on both the underlying characteristics of the economies (e.g., comparative advantages) and agglomeration forces (e.g., clustering of economic activities). For example, if trade agreements include only developing economies (south-south agreements), which suffer comparative disadvantages in manufacturing, and if this disadvantage is less for one member than for the others, the country with the least comparative disadvantage gains from the relocation because it can supply more manufacturing to a market that is protected from competition with the rest of the world. The others likely lose. ${ }^{6}$

\footnotetext{
5 Ventura (1997, p. 60) explains that in high-savings economies (e.g., East Asian countries during the 19601990 period), when "the capital stock grows, resources are moved from labor-intensive to capital-intensive industries, raising the demand for capital and sustaining the value of its marginal product. International trade converts an excess production of capital-intensive goods into exports, instead of falling prices".

6 Other countries also suffer from trade diversion because manufacturing production leaves and some manufactured goods, which previously were imported from other parts of the world, are now imported from the single partner country with the lesser comparative disadvantage.
} 
In addition, spatial clustering of economic activities results from the balance between centripetal and centrifugal forces (Venables 1999). The former consist of knowledge spillovers and other technological externalities, labor market pooling effects, and linkages between buyers and sellers. The latter encourage dispersed activities for two reasons: First, negative externalities, such as congestion and pollution may be associated with concentrations, and second, consumers may be located outside the centers of activity, which encourage dispersion when the trade barriers or transport costs are high. According to Venables (1999), agglomeration forces interact with comparative advantages, such that developing countries may be better served by north-south than by south-south free-trade agreements.

\subsection{Convergence or divergence?}

We paraphrase Grossman and Helpman (1991) with the following question: Does international trade lead to convergence or divergence? The answer is, it depends. Indeed, even if trade has a significant, positive impact on growth, that does not ensure that convergence will occur. If lower-income countries benefit more from trade than higher-income countries, convergence will occur. Conversely, if developing countries do not benefit from trade or obtain a lesser benefit than richer countries, trade will increase the gap between the rich and the poor countries, and increased trade will result in a process of divergence.

As Rodríguez and Rodrik (1999, p. 5) note, "the answer varies depending on whether the forces of comparative advantage push the economy's resources in the direction of activities that generate long-run growth (via externalities in research and development, expanding product variety, upgrading product quality, and so on) or divert them from such activities". So, if we reconsider Grossman and Helpman's argument, some IOZ countries can be pushed to open, and as their economies begin to specialize in traditional sectors, which employ many unskilled laborers, and abandon areas with higher qualifications, they will experience a comparative disadvantage compared with developed countries. That is, a scenario of this type will have negative effects on growth.

It is also possible that no absolute convergence of economies is observable but that local convergence properties are verified. This occurs with convergence clubs. A small number of steady states exist, and each country has a tendency to converge to one of them. At the theoretical level, the presence of clubs is characterized by multiple equilibriums. Some countries may reach optimal equilibrium, while other countries remain in low-income equilibriums, which are often called "poverty traps" (Kraay and Raddatz 2007). "A consequence of multiple equilibria is that a poor country cannot grow out of poverty unless some policy initiative is taken to change initial conditions in such a way that this country could "jump" from its low level, stable, initial equilibrium to another equilibrium, equally stable, characterized by a higher level of income" (Berthélemy 2006, p. 6). In addition, according to Winters et al. (2004, p. 76), "it is not difficult to construct models in which openness pushes countries into less dynamic sectors (e.g., primary extraction) and harms growth". In these conditions, the openness-growth-convergence link is an empirical matter (see, for example, Rey 2001). 


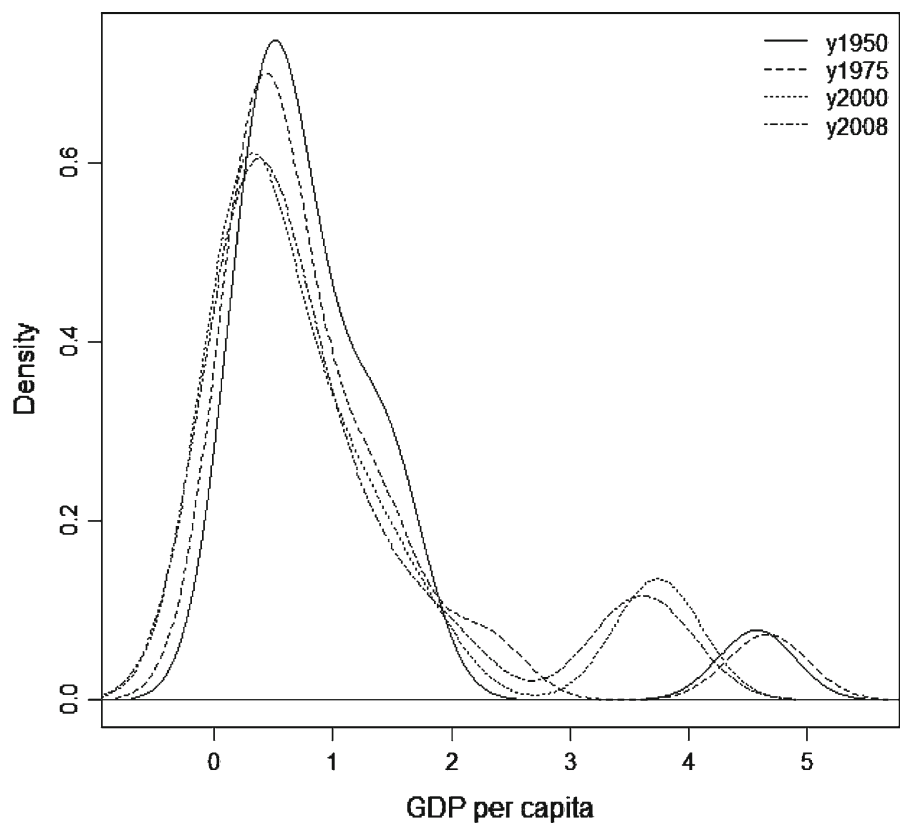

Fig. 1 Kernel density of relative income per capita

\section{Distributions of per capita incomes: the emergence of polarization}

To describe how the distribution of income across countries has changed over time and to highlight the polarization phenomenon, we use kernel density estimates ${ }^{7}$ of relative per capita incomes, which should provide an initial idea about the income dynamics of the IOZ. We complete the presentation of kernel densities by multimodality tests.

\subsection{Kernel density}

We analyze the distribution of relative GDP per capita, that is, the distribution of the ratios between GDP per capita of each country and GDP per capita of the IOZ average. We use a kernel distribution to highlight the presence of several modes, where the modes represent groups of countries. However, the shape of the empirical density remains dependent on the choice of the smoothing parameter/bandwidth. Among different methods to estimate the bandwidth, we adopt the "rule-of-thumb" method with the variation recommended by Scott (1992). In Fig. 1, we provide the estimated density function of the relative GDP per capita for the initial year, as well as 1975 ,

\footnotetext{
7 The kernel estimator is a smoothed version of the histogram used to estimate a probability density function $f$ of a random walk variable $X$. Given a sample $X 1, X 2, \ldots, X n$ of independent and identically distributed observations, the fixed estimator for the density function at point $x$ is $f(x)=\frac{1}{n . h} \sum_{i=1}^{n} K\left(\frac{x-X i}{h}\right)$, where $h$ is the bandwidth (smoothing parameter) and $K$ is the kernel function. The kernel function we use is Gaussian (Silverman 1986).
} 
Table 1 Results of bootstrap multimodality tests

\begin{tabular}{lllllllll}
\hline Year & \multicolumn{2}{l}{ BW critical $\left(\hat{h}_{m}\right)$} & \multicolumn{3}{l}{$p$ value } & Values of the modes \\
\cline { 2 - 3 } \cline { 7 - 8 } & $m=1$ & $m=2$ & $m=3$ & & $m=1$ & $m=2$ & $m=3$ & \\
\hline 1950 & 1.0164 & 0.2554 & 0.1706 & 0.016 & 0.224 & 0.278 & $0.48 ; 4.57$ \\
1975 & 0.9657 & 0.3037 & 0.2408 & $0.074 *$ & 0.356 & 0.156 & $0.42 ; 4.66$ \\
2000 & 0.8674 & 0.2141 & 0.1886 & $0.068 *$ & 0.724 & 0.282 & $0.24 ; 3.73$ \\
2008 & 0.7909 & 0.2491 & 0.2036 & 0.112 & 0.652 & 0.292 & 0.52 \\
\hline
\end{tabular}

* Significant at the $10 \%$ level

$B W$ bandwidth

2000, and 2008. A simple observation shows that the distributions seem bimodal in 1950, 1975, 2000, and 2008. However, in line with Silverman (1981), we can test for the existence of multiple modes with a bootstrap test.

\subsection{Multimodality tests}

Table 1 presents the results of the bootstrap multimodality test. ${ }^{8}$ The results indicate that the hypothesis of bimodality of relative GDP per capita could not be rejected at a $10 \%$ significance level in 1950, 1975, and 2000. In 2008, the result suggests unimodal distribution. However, the $p$ value is equal to 0.11 , which is close to the 0.10 level assumed by the null hypothesis. In addition, these estimates by year confirm both the bimodality and a reduction of the gap between the mode of lowest-income countries and highest-income countries. Therefore, if there is a convergence process, it is very slow and occurs over time. The study of the convergence process should enhance these observations.

\section{Concepts of convergence and methodology}

Given the various criticism on cross-section and panel data approaches, ${ }^{9}$ we will consider successively the stochastic convergence and the dynamics distribution approach.

\subsection{Stochastic convergence}

We test the existence of an "equilibrium" relationship among incomes over the period considered. Let $y_{i t}$ be the real per capita GDP for economy $i(i=1, \ldots, N)$, and let $\mu_{t}$ be the sample mean of $\log \left(y_{i, t}\right)$, with $\mu_{t}=N^{-1} \sum_{i=1}^{N} \log \left(y_{i, t}\right)$. Stochastic convergence occurs if the difference between the log of real per capita GDP for a country $i$ and the log of real per capita GDP for a "benchmark country" follows a stationary process. In the first case, we retain the sample mean as a "benchmark". So,

\footnotetext{
8 See Appendix 1 for a presentation of the test.

9 See for example Durlauf 2003; Islam 2003; Costantini and Lupi 2005.
} 
Table 2 Independent panel unit-root tests: 1950-2008

\begin{tabular}{|c|c|c|c|c|}
\hline \multirow[t]{3}{*}{ Method } & \multicolumn{4}{|c|}{ "Benchmark"country GDP } \\
\hline & \multicolumn{2}{|c|}{ Sample mean GDP } & \multicolumn{2}{|c|}{ World GDP } \\
\hline & Statistic & $p$ Value $^{\mathrm{a}}$ & Statistic & $p$ Value $^{\mathrm{a}}$ \\
\hline \multicolumn{5}{|c|}{ Null: Unit root (assumes common unit-root process) } \\
\hline Levin, Lin \& Chu modified $t$-statistic & 1.36643 & 0.9141 & 0.42406 & 0.6642 \\
\hline Breitung $t$-statistic & 3.98295 & 1.0000 & 4.06685 & 1.0000 \\
\hline \multicolumn{5}{|c|}{ Null: Unit root (assumes individual unit-root process) } \\
\hline Im, Pesaran and Shin $W$-statistic & 4.49650 & 1.0000 & 3.58992 & 0.9998 \\
\hline ADF_-Fisher chi-square & 11.4201 & 0.9997 & 14.2877 & 0.9971 \\
\hline PP_Fisher chi-square & 8.45253 & 1.0000 & 12.9143 & 0.9989 \\
\hline \multicolumn{5}{|c|}{ Null: No unit root (assumes common unit-root process) } \\
\hline Hadri $Z$-statistic & 18.6487 & 0.0000 & 17.9780 & 0.0000 \\
\hline
\end{tabular}

a Probabilities for Fisher tests are computed using an asymptotic chi-square distribution. All other tests assume asymptotic normality. Exogenous variables: Individual effects.

$A D F$ Augmented Dickey-Fuller test, and PP Phillips-Perron

stochastic convergence implies that $\left(\log \left(y_{i, t}\right)-\mu_{t}\right)$ is $\mathrm{I}(0)$, when $\log \left(y_{i, t}\right)$ is $\mathrm{I}(1)$. In the second case, we view the world as a "benchmark". Indeed, it is possible that we observe dynamics in GDP per capita that differ depending on whether we consider the process between IOZ countries only or between IOZ countries and the rest of the world. We adopt the panel unit-root procedure to test stochastic convergence. We can distinguish two categories of tests in the literature. The first category assumes that the cross-sectional errors are independent. The second category accounts for crosssectional dependence in errors. Because IOZ countries have strong linkages, it may be useful to apply these two categories of tests. In the first case, we apply the tests that Levin et al. (2002), Breitung (2000), Im et al. (2003), and Hadri (2000) developed, and in the second case, we apply the dependent panel unit-root tests of Choi (2006), Bai and Ng (2004), Pesaran (2004), and Moon and Perron (2004). Costantini and Lupi (2005) and Hurlin and Mignon (2005) highlight most of these tests, ${ }^{10}$ so we do not present them in detail; rather, we focus on the interpretation of results.

Table 2 presents the panel unit-root tests results for the two "benchmark" countries; these tests assume that the cross-sectional units are independent of each other. In all cases, the null hypothesis of unit root in the pairwise differences between "benchmark" per capita real GDP and the per capita real GDP of $i$ countries is not rejected, while the stationary hypothesis (Hadri's test) is rejected. This conclusion is valid for both the sample mean GDP and the world GDP as "benchmarks".

However, sometimes it is necessary to relax the independence hypothesis and assume cross-sectional dependence (CD). To verify the validity of this assumption, we

\footnotetext{
10 These tests use Matlab software and programs that Hurlin developed (see http://www.univ-orleans.fr/ deg/masters/ESA/CH/churlin_E.htm).
} 
use two tests: a CD test of Breusch and Pagan (1980) and a CD test of Pesaran (for a discussion, see De Hoyos and Sarafidis 2006; Pesaran 2004). Breusch and Pagan (1980) proposed a Lagrange-multiplier statistic for testing the null of zero cross-equation error correlations. This statistic (noted CD_BP) is as follows:

$$
\text { CD_BP }=T . \sum_{i=1}^{N-1} \sum_{j=i+1}^{N} \hat{\rho}_{i j}^{2} \sim \chi^{2} \text { with } N(N-1) / 2 \text { degrees of freedom, }
$$

where $\hat{\rho}_{i j}$ is the sample estimate of the pairwise correlation of the residuals. "Recognizing the shortcoming of the Breusch and Pagan's [Lagrange-multiplier] test when $N$ is large", Pesaran (2004) proposes the following statistic (noted CD_Pes):

$$
\text { CD_Pes }=\sqrt{\frac{2 T}{N(N-1)}} \cdot \sum_{i=1}^{N-1} \sum_{j=i+1}^{N} \hat{\rho}_{i j} \sim N(0,1) \text {. }
$$

This equation is based on the pairwise correlation coefficients rather than their squares. We obtain CD_BP $=4.59$ and CD_Pes $=229.44$, respectively, and their critical values are 1.96 and 124.3. We reject the null hypothesis of zero cross-sectional dependence. Therefore, it is necessary to relax this hypothesis and account for cross-sectional dependence. For this, we proceed to test for cross-sectionally correlated panels. Table 3 presents the results of these tests. In all cases, note that the null hypothesis of the unit root cannot be rejected. This confirms previous conclusions that there is no convergence process toward the sample mean GDP or the world GDP. But if no global convergence has occurred, it does not exclude the possibility that convergence has taken place at a more limited level. In these circumstances, it may be desirable to investigate possible convergence processes within the IOZ (convergence clubs). For this purpose, an analysis of income dynamics may be particularly appropriate.

\subsection{Distribution dynamics approach}

In the dynamic approach, Markov chains approximate and estimate the laws of distribution. The intradistributional mobility can be estimated with stochastic kernels and transition probability matrices. The transition probability represents the discrete model, and the stochastic kernel is its continuous version. The per capita GDP observations for each economy also are normalized to the average level of per capita GDP among the 16 countries. Therefore, the dynamics of the cross-regional income distribution $(F)$ can be modeled as an $\mathrm{AR}(k)$ process, as follows:

$$
F_{t+k}=T\left(F_{t}\right)
$$

where $T$ denotes the operator mapping period's $t$ distribution into the period's $t+k$ distribution. This operator can be interpreted as either the transition probability matrix of a discrete state-space Markov process or the transition function of a continuous state-space Markov process (stochastic kernel). Because the transition probabilities 
Table 3 Dependent panel unit-root tests: 1950-2008

\begin{tabular}{|c|c|c|c|c|c|}
\hline \multirow[t]{3}{*}{ Null: Unit root } & & \multicolumn{4}{|c|}{ "Benchmark"country GDP } \\
\hline & & \multicolumn{2}{|c|}{ Sample mean GDP } & \multicolumn{2}{|c|}{ World GDP } \\
\hline & & Statistic & $p$ Value $^{\mathrm{a}}$ & Statistic & $p$ Value $^{\mathrm{a}}$ \\
\hline Panel test & Statistic & & & & \\
\hline \multirow[t]{3}{*}{ Choi $^{\mathrm{a}}$} & $P m$ & -1.0505 & 0.8533 & -0.7745 & 0.7807 \\
\hline & $Z$ & 1.2655 & 0.8971 & 0.9343 & 0.8249 \\
\hline & $L^{*}$ & 1.2041 & 0.8857 & 0.8591 & 0.8049 \\
\hline \multirow[t]{2}{*}{ Moon \& Perron ${ }^{b}$} & $t_{a}^{*}$ & 0.3237 & 0.6269 & 0.2430 & 0.5960 \\
\hline & $t_{b}^{*}$ & 5.8147 & 1.0000 & 3.8661 & 0.9999 \\
\hline \multirow[t]{2}{*}{ Bai \& $\mathrm{Ng}^{\mathrm{c}}$} & PCe_Choi & -2.5103 & 0.9940 & -1.8411 & 0.9672 \\
\hline & PCe_MW & 11.9179 & 0.9995 & 17.2716 & 0.9842 \\
\hline \multirow[t]{3}{*}{ Pesaran $^{\mathrm{d}}$} & CIPS $p=1$ & -0.5129 & 0.9900 & -0.8182 & 0.9900 \\
\hline & $p=2$ & -0.5377 & 0.9900 & -0.7692 & 0.9900 \\
\hline & $p=3$ & -0.6403 & 0.9900 & 0.9539 & 0.9900 \\
\hline
\end{tabular}

${ }^{a}$ Lag selection in the augmented Dickey-Fuller/generalized least squares (ADF-GLS) test is determined using the Bayesian information criterion

$\mathrm{b} t_{a}^{*}$ and $t_{b}^{*}$ tests are computed using a quadratic spectral kernel

c PCe_Choi is a pooled test standardized statistic on idiosyncratic components $(N[0,1]$ under $H 40)$. PCe_MW is a pooled tests statistic on idiosyncratic components (Maddala and Wu $1999 ; \chi^{2}$ at $2 N$ degrees of freedom under $\mathrm{HO}$ )

$\mathrm{d}$ The CIPS test is the mean of individual cross-sectional ADF statistics. The truncated statistics (CIPS*) are not reported because they are always equal to the non-truncated ones. $p$ denotes the nearest integer of the mean of the individual lag lengths in $\mathrm{ADF}$ tests

resulting from the Markov matrix can be distorted by an inappropriate discretization (i.e., choice of states; Bulli 2001), we retain the stochastic kernel approach, which constitutes the continuous equivalent of the transition probability matrix. So, we can estimate the frequency distribution for a large number of overlapping class intervals (or windows), which give the appearance of a probability density function. The stochastic kernel measures transition probabilities on a finer grid, with a representation as a surface in three dimensions, which may be interpreted to reflect the possibilities of economies moving up or down the rankings of the distribution over a period from $t$ to $t+k$. On the $x$-axis, we plot the $t$ period's deviations from the cross-regional mean, and on the $y$-axis, we plot the $t+k$ period's income deviations from the cross-regional mean. On the $z$-axis, we plot the conditional transition density function associated with the stochastic kernel. Multiple methods exist to estimate these stochastic kernels.

Hyndman et al. (1996) propose several changes to traditional estimations of the conditional kernel, using two new tolls to represent the conditional density: stacked and HDR plots. The plots obtained with this approach are "more informative than the traditional displays of three-dimensional functions (e.g., contours plots or threedimensional perspective plots)" (Hyndman et al. 1996, p. 327).

Stacked plots depict the stochastic kernel in terms of a three-dimensional, stacked, conditional density plot in which multiple conditional densities appear side by side in 
a perspective plot. For any point $x$ on the period $t$ axis, observations in the direction parallel to the $t+k$ time axis trace a conditional probability density. The graph shows how the cross-sectional income distribution at time $t$ evolves into that at time $t+k$. As with a transition probability matrix in a discrete setup, the 45-degree diagonal in the graph indicates persistence properties. When most of the graph appears concentrated along this diagonal, the elements in the cross-sectional distribution remain where they started (Fischer and Stumpner 2008; Laurini and Valls Pereira 2007).

The HDR plot addresses the smallest region of the sample space that contains a given probability. These regions provide a visual summary of the characteristics of a probability distribution function (Basile 2010), such that each vertical band represents the projection on the $x y$ plane of the conditional density of $y$ on $x$. The plots of $50 \%$ (darker shaded), 90\%, and 99\% (lighter shaded) HDR can be computed from the density estimate. An HDR reflects the smaller region in the sample space that contains a given probability, ${ }^{11}$ and the mode of each conditional estimate (highest for multimodal distributions) is superimposed on the HDR plots as bullets.

To analyze the intradistribution dynamics and convergence along a period of length $k$, HDR plots are useful (Arbia et al. 2006; Basile 2009, 2010) because they allow for a discussion of strong persistence when the elements remain where they started (i.e., when the 45-degree diagonal crosses the 50\% HDR); weak persistence and more intradistribution mobility when the diagonal crosses only the 90 or $99 \%$ HDR; strong (weak) global convergence when the horizontal line traced at 1.0 of the period $t+k$ axis crosses all the 50\% (90-99\%) HDRs; and finally strong (weak) local or club convergence when some 50\% (90-99\%) HDRs are crossed by a horizontal line traced at any value of the $t+k$ axis.

In Fig. 2, we show the kernel density estimated for a 10 -year transition period. ${ }^{12} \mathrm{We}$ retain 10 years for the transition period because the mobility can be limited for shorter transition periods (e.g., 1 or 5 years). The stacked density plot in Fig. 2 a reveals a probability mass along the main diagonal for the poorest countries, with some apparent deviations from this diagonal for higher relative incomes. In addition, Fig. 2a shows a bimodality that the HDR plot may confirm ${ }^{13}$. In Fig. $2 b$, we observe both persistence and mobility with polarization features: Persistence is evident among countries with relative incomes between 0.1 and 1.8 times the average per capita income and among the richest countries whose relative income is greater than 4.5 times the average income. The mass of the probability is concentrated around the diagonal. Conversely, we identify one convergence club for countries whose incomes reach approximately 2.0-4.5 times the average (Australia, Malaysia, Mauritius, Singapore, and Thailand). For incomes between 2.0 and 3.0 times the average income, we note clockwise movement, indicating a convergence process by which these countries work to catch up

\footnotetext{
11 Let $f(x)$ is the density function of a random variable $X$. Then, the $100(1-\alpha) \%$ HDR is the subset $R\left(f_{\alpha}\right)$ of the sample space of $X$, such that $R\left(f_{\alpha}\right)=\left\{x: f(x) \geq f_{\alpha}\right\}$ and $f_{\alpha}$ is the largest constant, with $\operatorname{Pr}\left[X \in R\left(f_{\alpha}\right)\right] \geq 1-\alpha$ (Hyndman 1996).

12 The kernel is Gaussian, and the bandwidths can be computed according to the rules of Bashtannyk and Hyndman (2001) and Hyndman and Yao (2002). To calculate the plots, we used the R package hdrcde.

13 The HDR appears more informative in terms of representing changes in the distribution, and thus we retain only the HDR plots subsequently.
} 

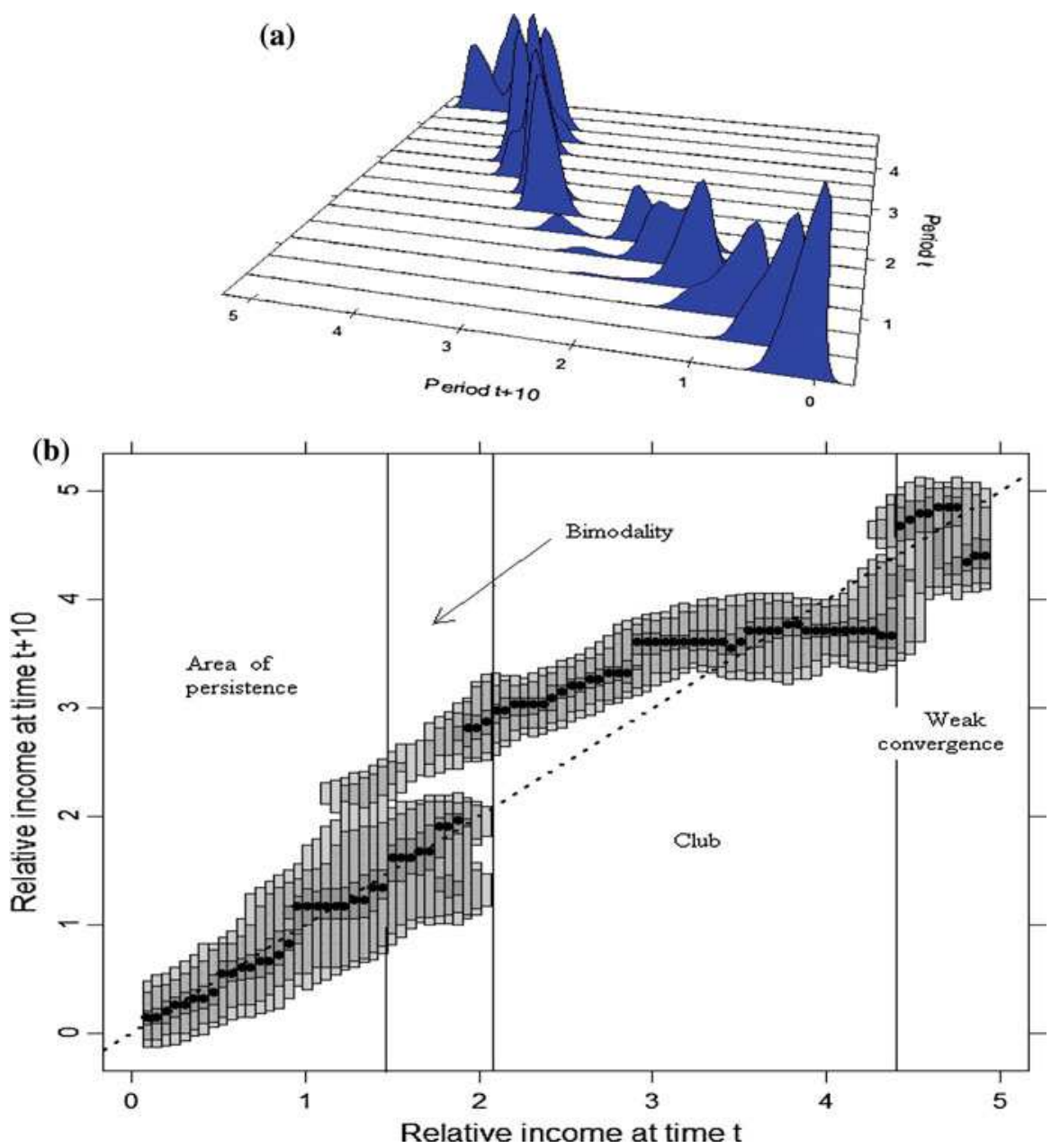

Fig. 2 Stacked density (a) and HDR (b) of relative (per capita) income dynamics across 16 IOZ countries

with the countries with superior incomes. In the countries with incomes between 3.0 and 4.5 times, the average income in period $t$, we observe a weak convergence process that we explain as the decline of the Australian relative income.

However, even if the emergence of a convergence club can be displayed and described by the stochastic kernel, it cannot be explained directly. By extending the stochastic kernel, we attempt to identify the factors that may induce the coalitions (Quah 1997).

\section{Conditional convergence}

A traditional conditional convergence approach justifies the additional right-hand side variables (auxiliary variables) in a convergence regression, which in turn are justified 
by an intuition that those variables should affect long-term growth (Quah 1996a). Similarly, because we study the distribution of incomes, we construct conditioned distributions.

\subsection{Measuring conditioned distributions}

If $Y$ represents original observations about relative per capita incomes (unconditioned in Quah's terms), then $Y / \Theta=\tilde{Y}$ is the conditioned version and $\Theta$ is the conditioning scheme, such that $\tilde{Y}$ is defined as $\tilde{Y}(t)=y(t) / \hat{y}(t)$, where $\hat{y}(t)$ is the conditioned per capita income. The difficulty is in obtaining an estimate of $\hat{y}(t)$. In practical terms, $\hat{y}(t)$ can be expressed as a weighted sum of the GDPs of different countries, where the weights $\omega$ differ according to the conditioning process. So for a country $j, \hat{y}_{j}(t)$ may be defined as

$$
\hat{y}_{j}(t)=\sum_{i} \omega_{i, j}(t) \cdot y_{i}(t) .
$$

We retain two conditioning schemes to measure the weights $\omega_{i, j}$.

First, we can define subsets $\left(C_{j}\right)$ of IOZ that represent a collection of $i$ economies with characteristics similar to those of $j$ 's economy, but excluding $j$ itself. The $\omega_{i, j}$ then depends on membership in the subset, such that $\omega_{i, j}(t)=\left\{\begin{array}{ll}1 / n_{i, j} & \text { if } i \in C_{j}(t) \\ 0 & \text { elsewhere }\end{array}\right.$, where $n_{i, j}$ represents the number of countries $i$ included in $C_{j}$. This method is applied in three cases: manufactured exports conditioning, Sachs and Warner criteria conditioning, and participation in trade agreements conditioning.

Second, for bilateral trade conditioning, the $\omega_{i, j}$ can be calculated as the share of each $i$ partner in the total trade of the country $j$.

Furthermore, the stochastic kernel $Y \rightarrow Y / \Theta$ describes the importance of trade factors for explaining cross-country income distribution dynamics, which enables us to identify factors that may produce coalitions (or clusters). To identify the effects of conditioning, we rely on changes in the shape of stochastic kernel. If trade effects account for a substantial part of the distribution, then the stochastic kernel mapping from the original (unconditioned) distribution to the conditioned distribution would depart from the identity map. In other words, if the conditioning variable is not influential, the conditioned distribution of the transformed variable will retain the same original characteristics: The probability mass will be concentrated along the 45-degree diagonal in a map obtained from tracing the conditioned distribution at period $t$ to the conditioned distribution at period $t+10$.

\subsection{Conditioning in distribution dynamics}

There are two principal methods to investigate the relationship between trade and growth, according to Baldwin (2003): analyze the direct impact of trade flows, or study the influence of the trade policy. 


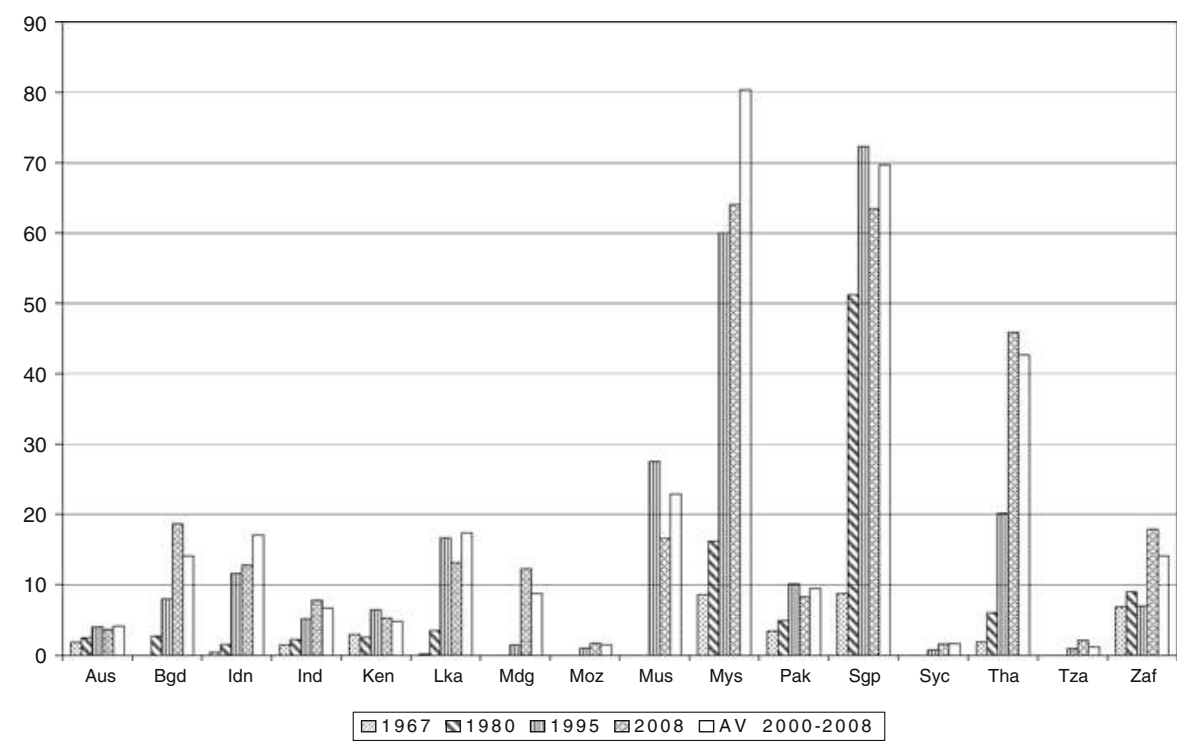

Fig. 3 Manufactured exports/GDP ratio (in \%)

\subsubsection{Influence of trade flows}

Economic theory identifies transmission channels between trade and Economic growth (Frankel and Romer 1999). Chuang (1998) and Coe et al. (1997) highlight the important role of learning on growth in relation to trade. Therefore, we consider two essential conditions for the interaction of trade with learning. First, both exports and imports are equally important sources and become mutually reinforced through intensification of the learning process. In addition, the nature or characteristics of the traded goods influence the effects of learning. Second, trade partners largely determine whether trade-induced technology spills over and actually affects enduring growth. On these bases, we consider groups of countries that take into account the nature of the trade, including the share of manufactured products, and the trade intensity among the IOZ countries, as marked by intrazone trade.

Manufactured exports/GDP conditioning. To form the groups, we consider countries according to their share of manufactured goods exports in terms of GDP. We do not consider a particular year, but we observe the share of manufactured goods exports over several years. Therefore, we retain these shares for 1967, 1980, 1995, and 2008 and the average across the 2000-2008 period. On this basis (see Fig. 3), we can distinguish three groups.

- Group 1 consists of countries with the highest manufactured exports/GDP ratios: Mauritius, Malaysia, Singapore, and Thailand.

- Group 2 comprises countries whose ratio is between 10 and 20\%: Bangladesh, Sri Lanka, Indonesia, Pakistan, and South Africa. 
(a)

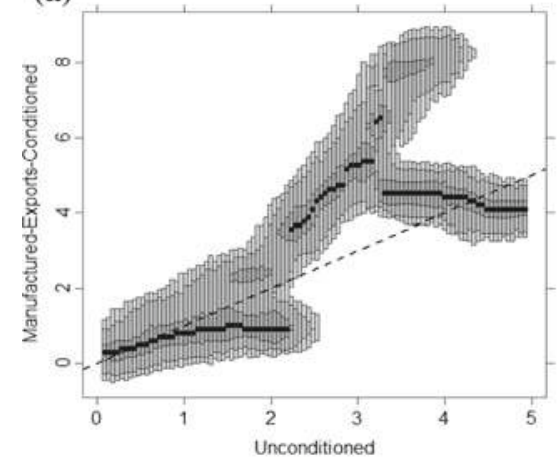

(b)

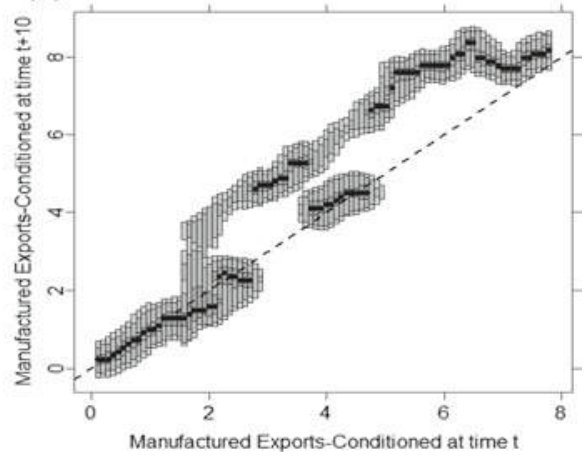

Fig. 4 HDR plots of unconditioned/manufactured exports conditioned and relative income dynamics for the conditioned distribution

- Group 3 comprises countries with the lowest manufactured exports/GDP ratios: Australia, India, Madagascar, Kenya, Mozambique, Seychelles, and Tanzania.

Figure 4 presents the results of manufactured exports conditioned relative income distributions. ${ }^{14}$ If the structure of trade accounts for a substantial part of the distribution, the stochastic kernel mapping from the original or unconditioned to the conditioned distribution would depart from the identity map. Figure 4a shows a clockwise movement of the higher part of the distribution and the lower part of the distribution. Two clubs appear. The first consists of the richest countries (i.e., countries that export manufactured goods, except for Australia), and the second comprises the poorest countries (i.e., countries that export few manufactured goods). Figure $4 \mathrm{~b}$ confirms the mobility of the distribution, with the exception of the lower extreme of the distribution and some intermediate incomes.

Bilateral trade conditioning. Rather than form groups, following Epstein et al. (2007), we obtain trade-conditioning GDP per capita series by normalizing each observation to a weighted average of the per capita incomes of the principal trading partners. In other words, the per capita GDP series are weighted with bilateral trade. So, we consider the weight of each $i$ trade partner in total trade of an $j$ country-that is, $\omega_{i, j}=\frac{T_{i, j}}{T_{j, \mathrm{IOZ}}}$, where $T_{i, j}$ represents the trade (exports plus imports) between $i$ and $j$ countries and $T_{j, \mathrm{IOZ}}$ is the trade between the $j$ country and all partners of the IOZ. The condition $\sum_{i} \omega_{i, j}=1$ is verified. The trade weights are calculated from the year $2000 .^{15}$

The HDR plots for conditioned/unconditioned relative income and the dynamic of the conditioned income in Fig. 5 do not show movement around the diagonal in panel a, which means that the cross-sectional per capita GDP distribution is not altered when we condition the data according to trade.

\footnotetext{
14 Because Mauritius belongs to group 1, its GDP will be normalized (divided) by the average GDP of Malaysia, Singapore and Thailand, and so on ....

15 Appendix 2 presents a table of weights.
} 
(a)

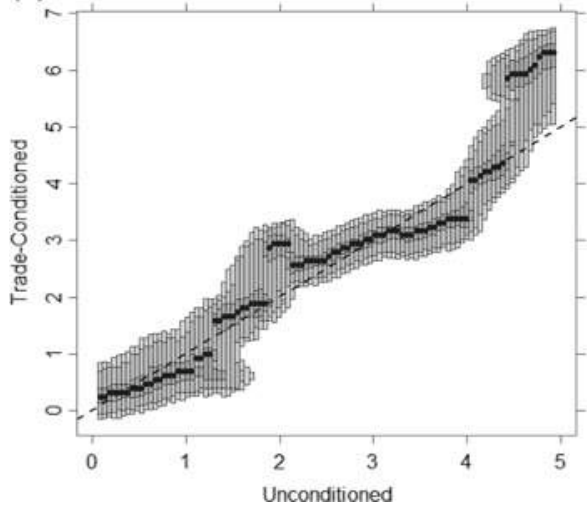

(b)

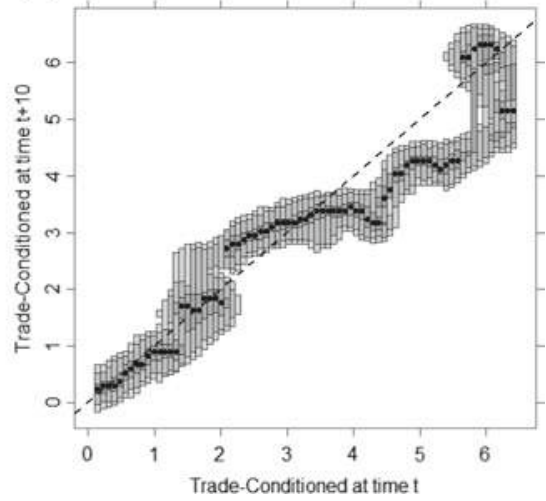

Fig. 5 HDR plots of unconditioned/bilateral trade intensity-conditioned and relative income dynamics for the conditioned distribution

Figure $5 \mathrm{~b}$ also provides the stochastic kernel representation of the 10-year transitions in the trade intensity-conditioned incomes. By comparing Figs. $2 \mathrm{~b}$ and $5 \mathrm{~b}$, we show that the distributions are very similar. Therefore, the intensity of trade does not provide an explanatory variable for the process of convergence. This distribution dynamics cannot explain the emergence of convergence clubs.

\subsubsection{Influence of trade policy}

Many studies attempt to classify countries according to their trade policies; yet various measures of trade policies persist (e.g., tariffs, quotas). These classifications also can be prone to controversies Pritchett (1996). Therefore, we consider the effects of trade policies by addressing either their openness or the participation of each country in trade agreements.

Openness conditioning. A high (low) degree of trade openness can be interpreted as a weak (strong) distortion of trade due to trade policy. We consider two openness measures: the ratio of trade to GDP and the Sachs-Warner criteria. The former is a traditional measure. Table 4 presents the degrees of openness measured as the sum of exports and imports divided by GDP. We retain an average openness rate over the whole period and then an openness rate over two subperiods, 1950-1979 and 1980-2007. The distinction of the openness rates enables us to estimate the distributions over these subperiods, which is useful because openness has not been a linear process since the 1950s. We classify the countries in three groups according to their openness degrees.

Therefore, we obtain the following:

Total period 1950-2007:

Group 1: Open <40\%: Australia, Bangladesh, India, Mozambique, and Pakistan. Group 2: Open <80\%: Indonesia, Kenya, Madagascar, South Africa, Sri Lanka, Tanzania, and Thailand.

Group 3: Open >80\%: Malaysia, Mauritius, Seychelles, and Singapore. 
Table 4 Degrees of openness $(X+M) / G D P$, averaged over the periods

Sources: lan Heston, Robert Summers and Bettina Aten, Penn World Table Version 6.3, Center for International Comparisons of Production, Income and Prices at the University of

Pennsylvania, August 2009

\begin{tabular}{lccc}
\hline & $1950-1979$ & $1980-2007$ & $1950-2007$ \\
\hline Australia & 29.22 & 36.56 & 32.77 \\
Bangladesh & 14.06 & 26.68 & 21.27 \\
India & 10.14 & 22.72 & 16.22 \\
Indonesia & 32.95 & 54.89 & 45.75 \\
Kenya & 47.79 & 48.89 & 48.32 \\
Madagascar & 42.25 & 49.18 & 46.29 \\
Malaysia & 78.50 & 158.64 & 120.84 \\
Mauritius & 93.65 & 121.07 & 106.89 \\
Mozambique & 15.20 & 46.42 & 33.41 \\
Pakistan & 19.90 & 29.99 & 24.77 \\
Seychelles & 136.37 & 143.40 & 140.47 \\
Singapore & 294.59 & 365.70 & 336.07 \\
South Africa & 57.27 & 50.66 & 54.08 \\
Sri Lanka & 73.32 & 72.56 & 72.96 \\
Tanzania & 42.19 & 42.20 & 42.20 \\
Thailand & 36.63 & 88.72 & 61.78 \\
\hline
\end{tabular}

First subperiod 1950-1979:

Group 1: Open <40\%: Australia, Bangladesh, India, Indonesia, Mozambique, and Pakistan.

Group 2: Open $<80 \%$ : Kenya, Madagascar, South Africa, Tanzania, and Thailand. Group 3: Open $>80 \%$ : Malaysia, Mauritius, Seychelles, Singapore, and Sri Lanka.

Second subperiod 1980-2007:

Group 1: Open <40\%: Australia, Bangladesh, India, and Pakistan.

Group 2: Open <80\%: Indonesia, Kenya, Madagascar, Mozambique, South Africa, Sri Lanka, and Tanzania.

Group 3: Open $>80 \%$ : Malaysia, Mauritius, Seychelles, Singapore, and Thailand.

In Fig. 6, we reveal the HDR plots for conditioned/unconditioned relative income (a) and the dynamic of conditioned income (b). We find a clockwise movement of the distribution parallel to the original axis, with four tendencies toward cohesion: (1) poorest countries at 0.2 times the average income, (2) inferior intermediate countries/incomes at 0.9 times the average income, (3) superior intermediate countries at 1.8 times the average income, and (4) richest countries at 3.4 times the average income. Figure $6 \mathrm{~b}$ confirms this evidence; the mass of the probability shows a mobility degree of the distribution, which increases with incomes and differs from the original/unconditioned distribution (Fig. 2b). That is, openness represents an explanatory variable for convergence clubs. However, the opening process was not linear during the period. Rather, it was initiated in the late 1970s and then continued during the 1980s, according to the countries. So, we split our sample into two subperiods, before and after 1980 (see Table 4). We chose 1980 because it can account fairly well for the average behavior of countries in the area. In addition, it enables us to work on two subsamples of comparable size. 
(a)

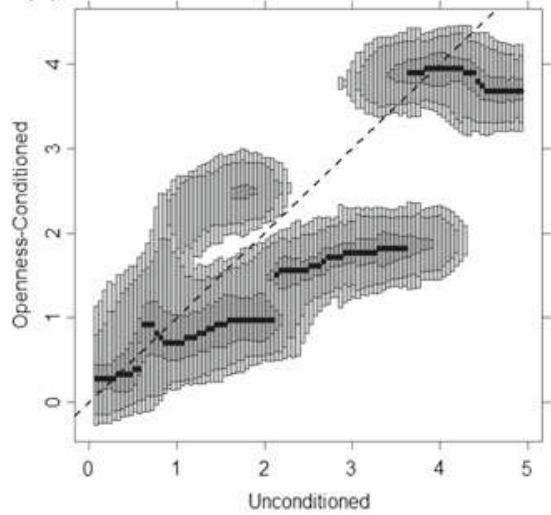

(b)

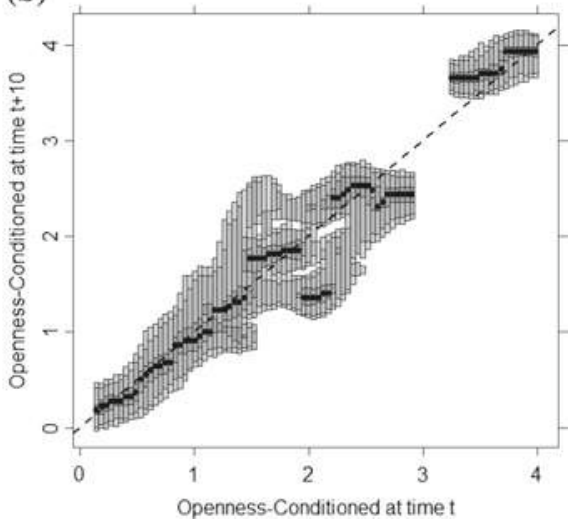

Fig. 6 HDR plots of unconditioned/openness conditioned and relative income dynamics for the conditioned distribution

(a)

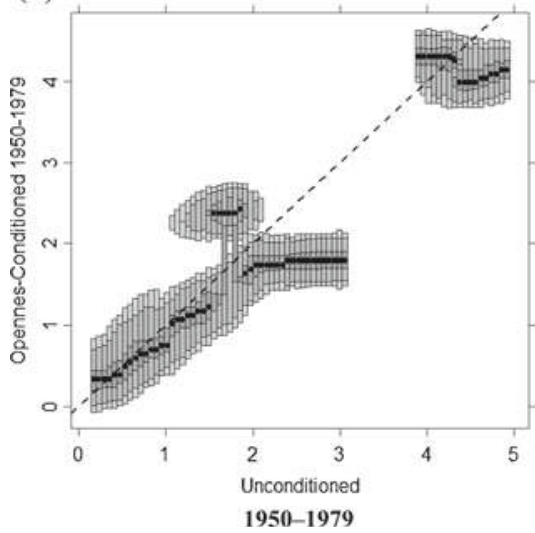

(b)

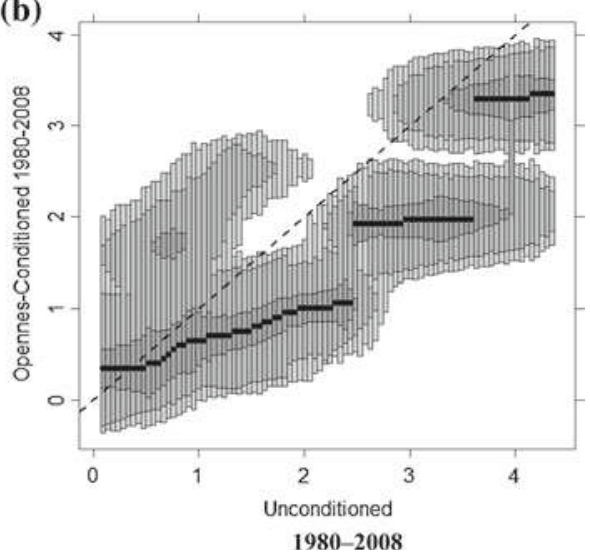

Fig. 7 HDR plots of unconditioned/openness conditioned for the subperiods

Because in each subperiod the number of observations is limited, we retain only the stochastic kernel representation of the conditioned/unconditioned relative. Figure 7 shows HDR plots for the 1950-1979 (panel a) and 1980-2008 (panel b) periods. The results differ significantly. For the 1950-1979 subperiod (Fig. 7a), the mass probability is concentrated around the diagonal for lowest incomes at 0.2 times to 1.6 times the average income. For highest incomes, at 2 times and 4 times the average income, we observe a clockwise movement of the distribution parallel to the original axis that reveals the emergence of clubs. These observations are confirmed and reinforced for the 1980-2008 subperiod (Fig. 7b). Figure 7 clearly shows the formation of clubs: two clubs rather than three? The response is difficult to precise, and it depends on the dynamics of lowest per capita GDP. On the one hand, we can consider the formation of a poorest-countries club; on the other hand, we can consider that the poorest countries catch up with the intermediate countries. To illustrate that effect, note that 
Table 5 Groups according to the Sachs-Warner criteria

Developing economies, always open

Malaysia, Thailand, Mauritius, Singapore

Developing economies, opened by 1994 after initial closure

Indonesia (1970), Kenya (1993), South Africa (1991), India (1994), Sri Lanka (1991)

Developing economies, closed at the end of 1994

Bangladesh, Madagascar, Mozambique, Pakistan, Tanzania

Developed economies, open

Australia (1964)

Source: Sachs and Warner (1995)

at the difference of the first subperiod, the clockwise movement is now observed for the lowest-incomes.

This evidence confirms that openness explains convergence clubs, especially during the past three decades in which the phenomenon of globalization has been realized.

Sachs and Warner criteria conditioning. The openness measure may not be appropriate when some countries' trade ratios reflect the nature of their factor endowment. Therefore, we adopt Sachs and Warner (1995) measure and propose several groups to estimate the kernel conditioning. Sachs and Warner classify countries as open (or closed) according to five criteria: ${ }^{16}$

1. Nontariff barriers covering less than $40 \%$ of traded goods.

2. Average tariff rates below $50 \%$.

3. A black market exchange rate of less than $20 \%$ of the official exchange rate.

4. Not a socialist country.

5. No extreme controls, taxes, quotas, or state monopolies on major exports.

According to these criteria, we derive the classification in Table 5 for the IOZ countries. We define the groups as those always open or open before 1975, open after 1975, and closed through 1994:

1. Malaysia, Thailand, Mauritius, Seychelles, ${ }^{17}$ Singapore, Indonesia, and Australia.

2. Kenya, South Africa, India, and Sri Lanka.

3. Bangladesh, Madagascar, Mozambique, Pakistan, and Tanzania.

Again, we find a clockwise distribution, especially for the superior part, in Fig. 8, such that openness effects help account for income dynamics in the IOZ. However, unlike the previous case (Fig. 6), we do not observe the formation of convergence clubs. Figure $8 \mathrm{~b}$ confirms this evidence.

Thus, we can consider that trade openness measured with a standard method (total trade/GDP ratio) has a better explanatory power of convergence than economic openness apprehended with broader criteria, such as those Sachs and Warner adopted.

16 Countries with different degrees of trade intervention can be classified as open (Edwards 1998).

17 Sachs and Warner (1995) do not classify Seychelles, but we view it as an open country and place it in Group 1. 
(a)

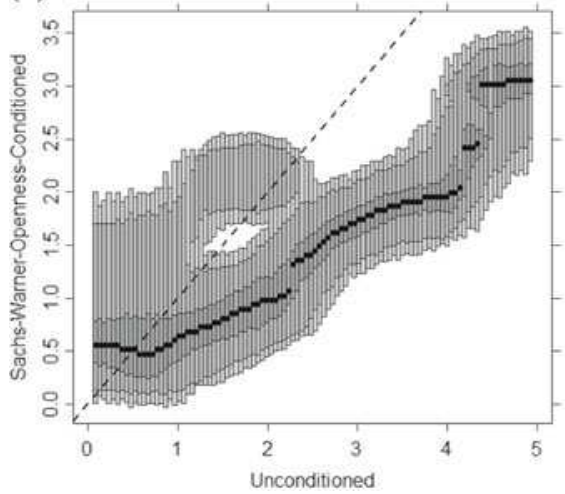

(b)

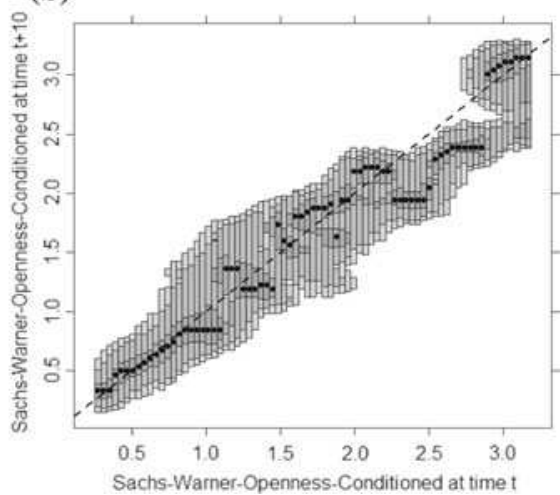

Fig. 8 HDR plots of unconditioned/Sachs-Warner classification conditioned and relative income dynamics for the conditioned distribution

Table 6 Groups according to trade agreement

\begin{tabular}{lc}
\hline Regional agreements & Countries \\
\hline SADC-COMESA & Mozambique, Mauritius, Seychelles, \\
& South Africa, Tazania, Kenya, \\
& Madagascar \\
APEC (or ASEAN) & Australia, Indonesia, Malaysia, \\
SAAR & Singapore, Thailand \\
& Bangladesh, India, Pakistan, \\
& Sri Lanka \\
\hline
\end{tabular}

Participation in trade agreements conditioning. Among the various trade agreements (noted TA, see Appendix 3), the IOR-ARC appears particularly important. Formed in 1997, it attempts to facilitate economic cooperation across its members, including both poor and richer countries in the IOZ. As do other agreements, the IOR-ARC works to remove restrictions on trade and investment within the zone, with the underlying idea that countries obtain benefits from trade liberalization. The constitution of the groups of countries, based on the regional agreements, indicates the classification in Table 6.

In Fig. 9, we reveal the HDR plots for unconditioned/TA-conditioned relative income (a) and the dynamic of TA-conditioned income (b).

The HDR plot for conditioned/unconditioned relative income in panel a do not show movement around the diagonal except for higher incomes. In addition, we do not observe the formation of convergence clubs. Figure $9 \mathrm{~b}$ confirms this evidence. The mass of the probability shows a low degree of mobility of the distribution. This evidence confirms that the trade agreements do not explain convergence clubs.

\section{Conclusion}

Unlike most studies on economic convergence that are interested in a large number of countries (i.e., the world) or many regions within a set of predefined countries 
(a)

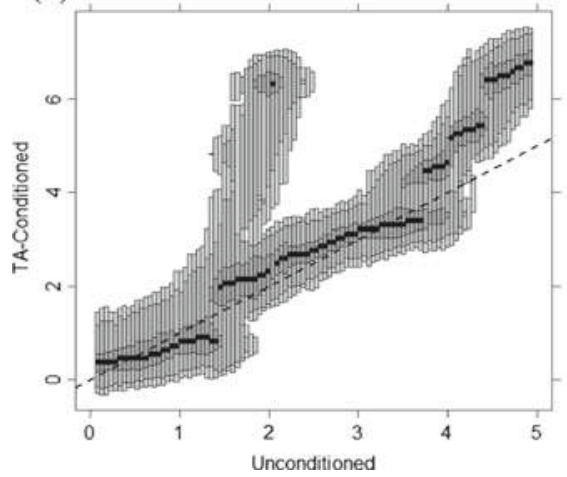

(b)

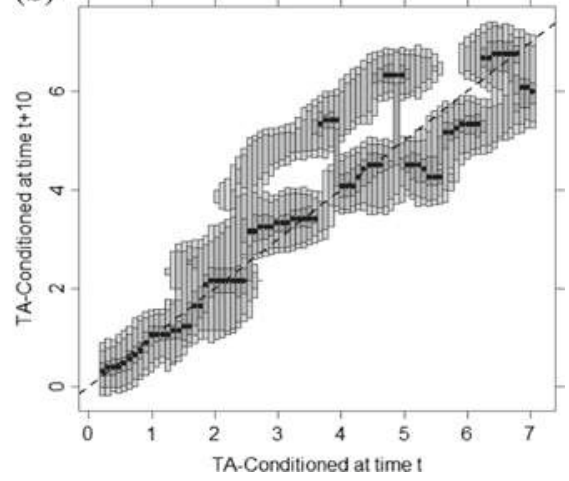

Fig. 9 HDR plots of unconditioned/TA conditioned and relative income dynamics for the conditioned distribution

(e.g., Europe) or within one country (e.g., China, India, United States), we focus on a set of countries that belong to the same geographical space, defined by the Indian Ocean. With this approach, we are able to highlight coalitions or clusters that would be very difficult to detect from a study of the world distribution of incomes per capita.

During 1950-2008, no absolute convergence process marked incomes across IOZ countries. Nevertheless, our findings suggest a bipolar situation. On the one hand, countries with the weakest relative incomes, in relation to the IOZ average, remain in the same relative position over time. India and Sri Lanka improve their positions slightly, as possible exceptions. On the other hand, the relatively richest countries constitute a convergence club, including Australia, Malaysia, Mauritius, Singapore, and Thailand, though Australia suffered a deterioration of its relative position.

Because of this zone's specificities, we attempt to verify whether international trade had an influence on the process of catching up, or convergence, among incomes. Given these estimates, it is clear that trade had a significant impact on the mobility distributions of income per capita of IOZ countries. Nevertheless, international trade can be captured by different indicators, all of which do not have the same explanatory power.

1. The openness rate, a proxy for trade policy, has a strong explanatory power. Thus, the trade/GDP ratio can explain the emergence of two or three clubs during the 1950-2008 period. This result is not as clear going back to the early 1950s. In addition, if the openness is approached using Sachs and Warner (1995) criteria, we find a clockwise movement of the distributions, but the emergence of clubs is less clear.

2. Conditioned distributions to manufactured goods exports reveal the emergence of two clubs. A group of richest countries that export manufactured goods (Australia is an exception) and a group of poorest countries that export few manufactured goods. However, this result likely confirms that the openness has been accompanied, for many of these countries, by an increase in manufactured goods trade. Our observations in Fig. 3 and Table 4 strengthen this conclusion. 
3. The consideration of bilateral trade reveals only a limited mobility of distributions, which mainly pertains to the highest-income countries. In addition, the trade agreements do not appear as an explanatory factor of the convergence clubs.

4. Finally, we show in this article that among the different criteria consideredtrade/GDP ratio, Sachs and Warner's openness criterion, manufactured goods exports, bilateral trade, participation in trade agreements - the trade/GDP ratio explains IOZ income dynamics best. This simple ratio offers greater explanatory power than a multicriteria indicator, as suggested by Sachs and Warner.

More generally, even if some criteria such as bilateral trade or trade agreements can explain part of income dynamics, namely, the dynamics of the highest incomes, they cannot explain changes observed among middle-income countries or for the lowest-income countries.

Moreover, we propose that the deterioration of Australia's position during the studied period may be due to insufficient openness. Similarly, Sachs and Warner (1995, p. 41) posit that "the apparent differences in long-run income levels are due to policies regarding economic integrations".

Globally, we argue that the poorest countries might find it beneficial to open their economies and reinforce their trade links with the richest countries in their trade zones. Doing so would offer an effective means for conducting a process of convergence across all IOZ countries, a process that would mainly benefit the countries that have suffered lags in their development.

This analysis also suggests that complementary studies would be useful. First, a critical characteristic of the IOZ is its unique geography. A spatial distance factor that accounts for this geography would extend and complement our work. Second, the links between trade and FDI may play decisive roles in the convergence process, a point that requires further consideration. Third, if FDI represents an explanatory factor, researchers would need to take the specializations of the IOZ countries into account, as well as their structural changes.

Acknowledgments The authors would like to thank the editor and two anonymous referees for their helpful and constructive comments.

\section{Appendix 1: Multimodality tests}

A key concept in kernel density estimation is the critical bandwidth. According to Bianchi (1997, p. 396), "A critical bandwidth $\hat{h}_{m}$ is defined as the smallest possible $h$ producing a density with at most $m$ modes, which means that for all $h<\hat{h}_{m}$ the estimated density $\hat{f}_{h}$ has at least $\mathrm{m}+1$ modes". We use $\hat{h}_{m}$ as a statistic to test the following:

$H_{0}: f(x)$ has $m$ modes against the alternative.

$H_{1}: f(x)$ has more than $m$ modes.

A large value of $\hat{h}_{m}$ indicates more than $m$ modes. Bootstrap methods are used to compute the $p$ value, or achieved significance level (ASL), associated with the test 
statistic $t(x)$. ASL is given by

$$
\mathrm{ASL}=\operatorname{Prob}_{\hat{F}_{0}}\left\{t\left(x^{*}\right) \geq t(x)\right\}
$$

where $x^{*}=\left(x_{1}^{*}, x_{2}^{*}, \ldots, x_{n}^{*}\right)^{\prime}$ is the bootstrap sample drawn from the null distribution $\hat{F}_{0}{ }^{18}$.

\section{Appendix 2: Weights to calculate trade-weighted GDP per capita}

Table A2 Weights to calculate trade-weighted GDP per capita according to bilateral trade (in \%, Year 2000)

\begin{tabular}{lccccccccccccccccc}
\hline & Aus & Bgd & Idn & Ind & Ken & Lka & Mdg & Moz & Mus & Mys & Pak & Sgp & Syc & Tha & Tza & Zaf \\
\hline Aus & & 0.92 & 17.80 & 11.52 & 0.19 & 0.28 & 0.02 & 0.03 & 0.44 & 19.82 & 1.48 & 25.34 & 0.02 & 14.47 & 0.33 & 7.33 \\
Bgd & 6.42 & - & 8.99 & 41.38 & 0.03 & 0.29 & - & - & 0.01 & 7.40 & - & 28.79 & - & 6.31 & 0.06 & 0.33 \\
Idn & 16.94 & 1.23 & - & 9.05 & 0.37 & 0.94 & 0.18 & 0.05 & 0.24 & 16.97 & 1.54 & 38.33 & 0.02 & 12.02 & 0.28 & 1.85 \\
Ind & 13.89 & 7.17 & 11.47 & - & 1.33 & 5.38 & 0.09 & 0.34 & 1.21 & 16.35 & 1.50 & 20.66 & 0.04 & 7.24 & 1.19 & 12.13 \\
Ken & 2.64 & 0.06 & 5.33 & 15.32 & - & 0.30 & 34.10 & 0.21 & 0.63 & 2.59 & 5.45 & 3.85 & 0.15 & 2.28 & 8.68 & 18.42 \\
Lka & 2.48 & 0.37 & 8.86 & 40.05 & 0.20 & - & 0.04 & 0.00 & 0.20 & 10.99 & 2.84 & 22.70 & 0.02 & 9.23 & 0.03 & 1.98 \\
Mdg & 0.48 & - & 4.72 & 1.95 & 61.78 & 0.12 & - & - & 13.04 & 1.00 & - & 9.92 & 0.34 & 0.55 & 0.03 & 6.07 \\
Moz & 0.75 & - & 1.41 & 7.25 & 0.39 & 0.00 & - & - & 0.55 & 3.31 & - & 0.72 & 0.01 & 1.23 & 0.15 & 84.24 \\
Mus & 8.71 & 0.03 & 5.03 & 19.79 & 0.89 & 0.44 & 10.20 & 0.42 & - & 6.17 & 2.58 & 8.36 & 2.02 & 3.44 & 0.56 & 31.35 \\
Mys & 7.66 & 0.41 & 6.90 & 5.24 & 0.07 & 0.47 & 0.02 & 0.05 & 0.12 & - & 1.01 & 63.64 & 0.00 & 13.25 & 0.05 & 1.10 \\
Pak & 12.98 & - & 14.17 & 10.89 & 3.43 & 2.77 & - & - & 1.15 & 22.81 & - & 19.68 & 0.01 & 7.38 & 0.43 & 4.29 \\
Sgp & 8.09 & 1.32 & 12.86 & 5.46 & 0.09 & 0.81 & 0.13 & 0.01 & 0.14 & 52.51 & 0.72 & - & 0.04 & 16.84 & 0.03 & 0.96 \\
Syc & 3.33 & - & 3.11 & 6.77 & 2.02 & 0.40 & 2.48 & 0.04 & 18.91 & 0.18 & 0.14 & 22.89 & - & 8.72 & 0.11 & 30.91 \\
Tha & 11.45 & 0.72 & 10.00 & 4.75 & 0.13 & 0.81 & 0.02 & 0.04 & 0.14 & 27.13 & 0.67 & 41.79 & 0.04 & - & 0.11 & 2.20 \\
Tza & 8.91 & 0.22 & 7.97 & 26.20 & 16.65 & 0.09 & 0.04 & 0.15 & 0.75 & 3.15 & 1.32 & 2.84 & 0.02 & 3.74 & - & 27.96 \\
Zaf & 20.15 & 0.13 & 5.35 & 27.64 & 3.64 & 0.61 & 0.66 & 8.99 & 4.38 & 7.85 & 1.35 & 8.28 & 0.46 & 7.64 & 2.89 & - \\
\hline
\end{tabular}

For Bangladesh, Australia contributed to $6.42 \%$ of bilateral trade with IOZ countries

Data source: Comtrade base

Notes: $A U S=$ Australia, $Z A F=$ South Africa, $K E N=$ Kenya, $M D G=$ Madagascar, $M U S=$ Mauritius, $M O Z=$ Mozambique, SYC = Seychelles, $T Z A=$ Tanzania, $I D N=$ Indonesia, $I N D=$ India, $S G P=$ Singapore, $M Y S=$ Malaysia, $T H A=$ Thailand, $P A K=$ Pakistan, $B G D=$ Bangladesh, and LKA = Sri Lanka.

\section{Appendix 3: Regional agreements of IOZ countries}

Asia Pacific Economic Cooperation (APEC, 1989): Australia, Brunei Darussalam, Canada, Chile, China, Hong Kong (China), Indonesia, Japan, the Republic of Korea, Malaysia, Mexico, New Zealand, Papua New Guinea, Peru, the Philippines, the

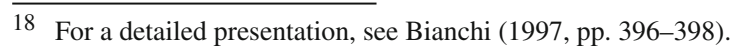


Russian Federation, Singapore, Taiwan (China), Thailand, the United States, and Vietnam.

Common Market for Eastern and Southern Africa (COMESA, 1993): Angola, Burundi, Comoros, the Democratic Republic of Congo, Djibouti, the Arab Republic of Egypt, Eritrea, Ethiopia, Kenya, Madagascar, Malawi, Mauritius, Namibia, Rwanda, Seychelles, Sudan, Swaziland, Uganda, Tanzania, Zambia, and Zimbabwe.

Indian Ocean Commission (IOC, 1984): Comoros, Madagascar, Mauritius, Reunion, and Seychelles.

Indian Ocean Rim Association for Regional Cooperation, (IOR-ARC, 1997): Australia, Bangladesh, India, Indonesia, Iran, Kenya, Madagascar, Malaysia, Mauritius, Mozambique, Oman, Reunion, Singapore, Sri Lanka, South Africa, Tanzania, Thailand, and U.A.E.

Southern African Development Community (SADC; formerly Southern African Development Coordination Conference, 1980): Angola, Botswana, the Democratic Republic of Congo, Lesotho, Malawi, Mauritius, Mozambique, Namibia, Seychelles, South Africa, Swaziland, Tanzania, Zambia, and Zimbabwe.

Association of South-East Asian Nations (ASEAN, 1967): Brunei, Cambodia, Indonesia, the Lao People's Democratic Republic, Malaysia, Myanmar, the Philippines, Singapore, Thailand, and Vietnam.

South Asian Association for Regional Cooperation (SAARC, 1985): Bangladesh, Bhutan, India, Maldives, Nepal, Pakistan, and Sri Lanka.

\section{References}

Arbia G, Basile R, Piras G (2006) Analyzing intra-distribution dynamics: a reappraisal. In: ERSA conference papers, European Regional Science Association

Bai J, Ng S (2004) A PANIC attack on unit roots and cointegration. Econometrica 72(4):1127-1177

Baldwin RE (2003) Openness and growth: what's the empirical relationship? NBER working paper number 9578

Baldwin RE, Seghezza E (1996) Trade-induced investment-led growth, NBER working paper number 5582

Bashtannyk DM, Hyndman RJ (2001) Bandwidth selection for kernel conditional density estimation. Comput Stat Data Anal 36(3):279-298

Basile R (2009) Productivity polarization across regions in europe: the role of nonlinearities and spatial. Int Reg Sci Rev 31:92-115

Basile R (2010) Intra-distribution dynamics of regional per capita income in Europe: evidence from alternative conditional density estimators. Statistica, 1

Bernard A, Durlauf SN (1996) Interpreting tests of the convergence hypothesis. J Econometrics 71:161-173

Berthélemy J-C (2006) Convergence clubs and multiple equilibria: how did emerging economies escape the under-development trap? Revue d'économie du dévelopement 20(5):5-41

Bianchi M (1997) Testing for convergence: evidence from non-parametric multimodality tests. J Appl Econometrics 12(4):357-457

Borenztein E, De Gregorio J, Lee JW (1998) How does foreign direct investment affect economic growth? $\mathrm{J}$ Int Econ 5(1):115-135

Bouët A, Laborde Debucquet D (2010) Economics of export taxation in a context of food crisis: a theoretical and CGE approach contribution, IFPRI Discussion Paper 00994, June

Breitung J (2000) The local power of some unit root tests for panel data. In: Baltagi B (ed) Advances in econometrics, vol. 15: nonstationary panels, panel cointegration, and dynamic panels. JAI Press, Amsterdam, pp 161-178

Breusch TS, Pagan AR (1980) The Lagrange multiplier test and its applications to model specification in econometrics. Rev Econ Stud 47(1):239-253 
Bulli S (2001) Distribution dynamics and cross-country convergence: a new approach. Scott J Polit Econ 48(2):226-243

Choi I (2006) Combination unit root tests for cross-sectionally correlated panels. In: Corbae D, Durlauf $\mathrm{SN}$, Hansen BE (eds) Econometric theory and practice: frontiers of analysis and applied research, Cambridge University Press, Cambridge

Chuang Y (1998) Learning by doing, the technology gap, and growth. Int Econ Rev 39(3):697-721

Coe DT, Helpman E (1995) International R\&D Spillovers. Eur Econ Rev 39(5):859-887

Coe DT, Helpman E, Hoffmaister AW (1997) North-South R\&D Spillovers. Econ J 107:134-149

Costantini M, Lupi C (2005) Stochastic convergence among European economies. Econ Bull 3(38):1-17

de Hoyos RE, Sarafidis V (2006) Testing for cross-sectional dependence in panel data models. Stata J StataCorpLP 64:482-496

Durlauf SN (1996) On the convergence and divergence of growth rates. Econ J 106(437):1016-1018

Durlauf SN (2003) The convergence hypothesis after 10 years. Working papers 6, The university of Wisconsin-Madison. http://www.ssc.wisc.edu/econ/archive/wp2003-06.pdf. (Spanish version published in Revista Economica de Castilla-La Mancha, 2, 55-75, 2003)

Easterly W, Kremer M, Pritchett L, Summers LH (1993) Good policy or good luck? Country growth performance and temporary shocks. J Monet Econ 32:459-483

Edwards S (1987) Economic liberalization and the equilibrium real exchange rate in developing countries, University of California, Los Angeles, Discussion paper number 433

Edwards S (1993) Openness, trade liberalization, and growth in developing countries. J Econ Lit 31(3):1358-1393

Edwards S (1998) Openness, productivity and growth: what do we really know? Econ J 108:383-398

Epstein P, Howlett P, Schulze M-S (2007) Trade, convergence, and globalisation: the dynamics of the international income distribution, 1950-1998. Explor Econ Hist 44:100-113

Fischer MM, Stumpner P (2008) Income distribution dynamics and cross-region convergence in europe: spatial filtering and novel stochastic kernel representations. J Geogr Syst 10(2):109-139

Frankel JA, Romer D (1999) Does trade cause growth? Am Econ Rev 89(3):379-399

Grossman G, Helpman E (1991) Innovation and growth in the global economy. MIT Press, Cambridge, MA

Hadri K (2000) Testing for stationarity in heterogeneous panel data. Econometrics J 3:148-161

Hurlin C, Mignon V (2005) Une synthèse des tests de Racine Unitaire sur Données de panel. Economie et Prévision 169-171:251-295

Hyndman RJ (1996) Computing and Graphing Highest Density Regions. Am Stat 50(2):120-126

Hyndman RJ, Bashtannyk DM, Grunwald GK (1996) Estimating and visualizing conditional densities. J Comput Graph Stat 5(4):315-336

Hyndman RJ, Yao Q (2002) Nonparametric estimation and symmetry tests for conditional density functions. J Nonparametr Stat 14:259-278

Im KS, Pesaran MH, Shin Y (2003) Testing for unit roots in heterogeneous panels. J Econometrics 115:5374

Islam N (2003) What have we learnt from the convergence debate? J Econ Surv 17(3):309-362

Kraay A, Raddatz C (2007) Poverty traps, aid, and growth. J Dev Econ 82(2):315-347

Krugman P (1985) A technology gap' model of international trade. In: Jungenfelt K, Hague D (eds) Structural adjustment in developed open economies. St. Martin's Press, New York

Laurini MP, Valls Pereira PL (2007) Conditional Stochastic Kernel Estimation by Nonparametric Methods. IBMEC working paper, São Paulo

Levin A, Lin CF, Chu C (2002) Unit root tests in panel data: asymptotic and finite-sample properties. J Econometrics 108:1-24

Levine R, Renelt D (1992) A sensitivity analysis of cross-country growth regressions. Am Econ Rev 82(4):942-963

Lucas R (1988) On the mechanisms of economic development. J Monet Econ 22:3-42

Maddala GS, Wu S (1999) A comparative study of unit root tests with panel data and a new simple test. Oxford Bull Econ Stat 61:631-652

Maddison A (2010) Historical statistics for the World economy: 1-2003 AD, http://www.ggdc.net/maddison

Miller SM, Upadhyay MP (2000) The effects of openness, trade orientation, and human capital on total factor productivity. J Dev Econ 63(2):399-423

Moon H, Perron B (2004) Testing for a unit root in panels with dynamic factors. J Econometrics 122:81-126 
Pesaran MH (2004) General diagnostic tests for cross section dependence in panels, Cambridge working, papers in economics no. 435, University of Cambridge, and CESifo working paper series no. 1229

Pritchett L (1996) Measuring outward orientation in developing countries: can it be done? J Econ Perspect 10(2):3-24

Quah DT (1996a) Convergence empirics across economies with (some) capital mobility. J Econ Growth 1(1):95-124

Quah DT (1996b) Twin peaks: growth and convergence in models of distribution dynamics. Econ J 106(437):1045-1055

Quah DT (1997) Empirics for growth and distribution: stratification, polarization and convergence clubs. J Econ Growth 2:27-59

Rey S (2001) Ouverture commerciale, taux de change réel et croissance dans les Pays Méditerranéens: les enseignements d'un modéle à correction d'erreur. In: Boudhiaf M, Siroën J-M (eds) Ouverture et développement économique, Economica, pp. 49-78

Rodríguez F, Rodrik D (1999) Trade policy and economic growth: a Skeptic's guide to the cross-national evidence, NBER working paper 7081, NBER, Cambridge, MA

Romer P (1986) Increasing returns and long-run growth. J Polit Econ 94:1002-1037

Sachs JD, Warner AM (1995) Economic convergence and trade policies. Brooking Pap Econ Act 1:1-95

Sala-i-Martin X (1990) On growth and states. PhD thesis, Harvard University, Cambridge MA

Sala-i-Martin X (1996a) The classical approach to convergence analysis. Econ J 106(437):1019-1036

Sala-i-Martin X (1996b) Regional cohesion: evidence and theories of regional growth and convergence. Eur Econ Rev 40:1325-1352

Scott DW (1992) Multivariate density estimation: theory, practice and visualisation. Wiley, London

Silverman BW (1981) Using kernel density to investigate multimodality. J R Stat Soc 43(1):97-99

Silverman BW (1986) Density estimation for statistics and data analysis. Chapman and Hall, London

Vamvakidis A (1999) Regional trade agreement or broad liberalization: which path leads to faster growth? IMF Staff Pap 46:42-68

Venables AJ (1999) Regional integration agreements: a force of convergence or divergence? In: Annual Bank conference on development economics, Paris, June

Venables AJ (2003) Winners and losers from regional integration agreements. Econ J 113:747-761

Ventura J (1997) Growth and interdependence. Q J Econ 112:57-84

Wacziarg R (1998) Measuring the dynamic gains from trade, Policy research working paper number 2001, World Bank

Winters A, McCulloch N, McKay A (2004) Trade liberalization and poverty: the evidence so far. J Econ Lit 42(1):72-115 